\title{
Homogeneity of the Test Variants in Entrance Exams
}

\author{
Jindřich $\mathrm{Klůfa}^{1}$ \\ ${ }^{1}$ University of Economics, Department of Mathematics, 13067 Prague, Czech Republic
}

\begin{abstract}
The problem of homogeneity of test variants in mathematics, which are used in admission process, is solved in present paper. The analysed data are the results of entrance examination in mathematics at University of Economics in Prague. Different statistical methods (test of hypothesis, correlation, regression) were used for this analyse. These results will be used to further improve of the preparation of test variants in the coming years.
\end{abstract}

Keywords. Entrance exams in mathematics, homogeneity of test variants, regression and correlation.

\section{Introduction}

For entrance examinations are frequently used the multiple choice question tests. Advantages of these tests: the multiple choice question tests are objective (there is clearly no impact of any subjective factor in evaluation) and results can be evaluated quite easily for large number of students. On the other hand, a student can obtain certain number of points in the test purely by guessing the right answers. This problem was analysed in [7], [16] and [18]. In [7] it was shown that risk of success of students with lower performance levels at University of Economics in Prague is negligible.

The difficulty of test variants for students is poorly measured. If we use the multiple choice question tests, the difficulty of test variants depends also on variants of answers from which the correct answer is chosen, e.g. the example

"combinatorial number $\left(\begin{array}{l}7 \\ 3\end{array}\right)$ is (a) 21 , (b) 35 , (c) 49" is more difficult than the example

"combinatorial number $\left(\begin{array}{l}7 \\ 3\end{array}\right)$ is (a) negative number, (b) zero, (c) positive number".

This problem shall be analysed for the test variants in mathematics which are used for the entrance examinations at University of Economics in Prague.

Test variants in mathematics are generated from a database created by the Department of Mathematics. The tests in mathematics at University of Economics have 10 questions for 5 points and 5 questions for 10 points (100 points total) - see [8]. Questions are independent. Each question has 5 answers (one answer is correct), wrong answer is not penalized. The number of points in the test in mathematics can be

$$
0,5,10,15,20,25,30,35,40,45, \ldots, 90,95,100 .
$$

These tests are used to the three faculties of the Prague University of Economics (Faculty of Informatics and Statistics, Faculty of Finance and Accounting, Faculty of Business Administration ). Analysis of the entrance examinations in mathematics in 2013 is provided in this paper (similar problems are solved in [2-6], [9-10], [12-13] and [15]. These results will be used to further improve of the preparation of test variants in the coming years.

\section{Entrance examinations at University of Economics}

The analysed data are the results of 4614 students in mathematics in 2013. Seventeen test variants were used for the entrance examinations in mathematics in 2013 (these test variants we can find in [8]). Part of one of them is on Figure 1. 


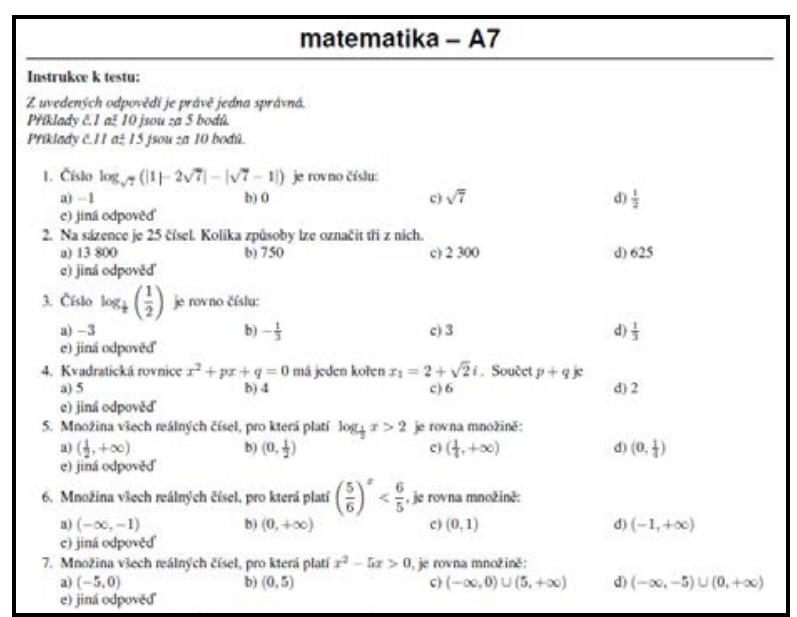

Fig. 1. Part of the variant A7 in mathematics in 2013

The test variants have 15 questions, each question has 5 answers - see Figure 1. Between these answers is the answer "e) another answer". If e) is correct answer, to mark the letter e may be for the students more complicated than to mark the letters a, b, c, d. For example solution of the question 1 in the test variant A7 (see Figure 1) is

$$
\log _{\sqrt{7}}((-1+2 \sqrt{7})-(\sqrt{7}-1))=\log _{\sqrt{7}}(\sqrt{7})=1
$$

i.e. the correct answer is e). The question 1 in the test variant A7 with variants of answers e.g.
a) 1
b) 0
c) $\sqrt{7}$
d) $\frac{1}{2}$
e) another answer

may be easier for students. Therefore we shall study the dependence of the number of points in the test in mathematics (denoted $\mathrm{Y}$ ) on the number of answers e) in tests variants (denoted $\mathrm{X}$ ).

\section{Results}

The number of answers e) in tests variants which were used for the entrance examinations at University of Economics in Prague in 2013 is 1, 2, 3, 4 and 5. Now we shall compare distributions of number of points in the test in mathematics in test variants with 1, 2, 3, 4 and 5 answers e) - see Figure 2 and Table 1.

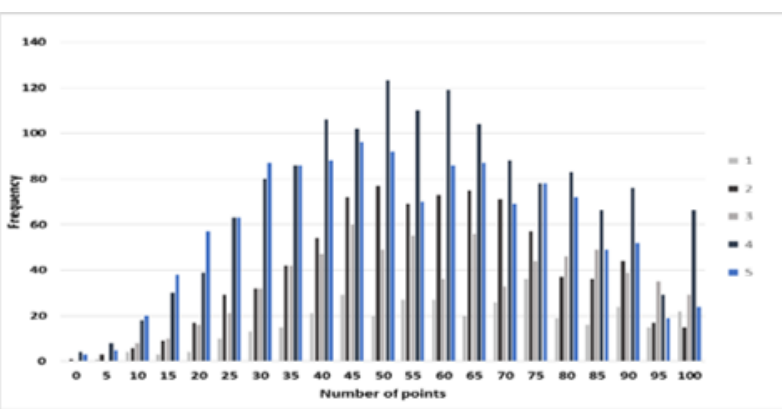

Fig. 2. Distribution of number of points in test in mathematics in 2013 in test variants with 1, 2, 3, 4 and 5 answers e) (histogram)
Tab 1. Distribution of number of points in test in mathematics in 2013 in test variants with 1,2, 3, 4 and 5 answers e) (source: own calculation)

\begin{tabular}{|c|c|c|c|}
\hline $\begin{array}{c}\text { Number of } \\
\text { answers e) }\end{array}$ & $\begin{array}{c}\text { Frequency } \\
\mathbf{n}_{\mathbf{i}}\end{array}$ & $\begin{array}{c}\text { Average } \\
\text { number } \\
\text { of } \\
\text { points }\end{array}$ & Variance \\
\hline 1 & 352 & 62.699 & 506.655 \\
\hline 2 & 836 & 57.829 & 419.742 \\
\hline 3 & 707 & 60.184 & 528.578 \\
\hline 4 & 1478 & 56.712 & 532.850 \\
\hline
\end{tabular}

Now we shall test null hypothesis

$$
\mathrm{H}_{\mathrm{o}}: \mu_{1=}=\mu_{2}=\mu_{3}=\mu_{4=} \mu_{5}
$$

where $\mu_{1}, \mu_{2}, \mu_{3}, \mu_{4}, \mu_{5}$ is mean number of points in mathematics in test variants with $1,2,3,4$ and 5 answers e), i.e. mean number of points in test variants with 1, 2, 3, 4 and 5 answers e) is the same.

To verify the validity of the hypothesis we use ANOVA. In the first step we verify assumption of this method by Bartlett's test (see e.g. [1]). The hypothesis "variance of number of points in mathematics in test variants with 1,2,3, 4 and 5 answers e) is the same" is not rejected at $1 \%$ significance level, assumption of ANOVA can be considered to have been met.

Results of ANOVA we got with MS Excel (e.g. [14]) see Table 2. Since

$$
F=19.422>2.374,
$$

the null hypothesis (1) is rejected at $5 \%$ significance level. There are some differences between the test variants with 1, 2, 3, 4 and 5 answers e), the differences between average number of points in test variants with $1,2,3,4$ and 5 answers e) in Table 1 are statistically significant.

Tab 2. Results of ANOVA (source: own calculation)

\begin{tabular}{|c|c|c|c|}
\hline $\begin{array}{c}\text { Source of } \\
\text { variability }\end{array}$ & $\begin{array}{c}\text { Test } \\
\text { variants }\end{array}$ & Rezidual & Sum \\
\hline $\begin{array}{c}\text { Sum of } \\
\text { Squares }\end{array}$ & 39486 & 2342608 & 2382094 \\
\hline $\begin{array}{c}\text { Degrees of } \\
\text { freedom }\end{array}$ & 4 & 4609 & 4613 \\
\hline Fraction & 9871.58 & 508.27 & \\
\hline F & 19.422 & & \\
\hline p value & $7.31 \mathrm{E}-16$ & & \\
\hline F crit & 2.374 & & \\
\hline
\end{tabular}




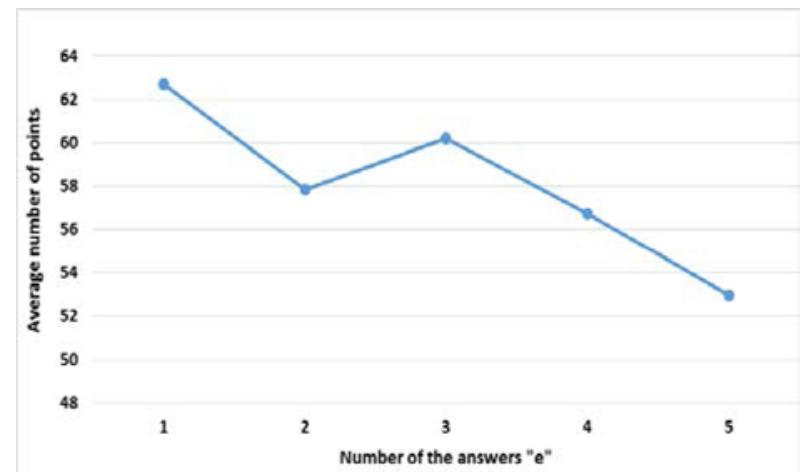

Fig. 3. Dependence of the average number of points in the test in mathematics on the number of answers e) in tests variants

From results of ANOVA it seems that $\mathrm{Y}=$ the number of points in the test in mathematics depends on $\mathrm{X}=$ the number of answers e) in tests variants. From Figure 3 it seems that dependence is linear, therefore we shall compute the correlation coefficient $r$ and regression line $y=a+b x$. Using MS Excel we have

$$
r=-0.112
$$

From this result follows that the dependence of the number of points in the test in mathematics on the number of answers e) in tests variants is weak or the dependence does not exist. Therefore we shall test null hypothesis

$$
\text { Ho: } \rho=0 \text {, }
$$

i.e. the number of points in the test in mathematics does not depend on the number of answers e) in tests variants. We shall compute - see e.g. [17]

$$
t=\frac{r}{\sqrt{1-r^{2}}} \sqrt{n-2}=-7.66
$$

Critical value of $t$ distribution for $n-2=4612$ degrees of freedom and significance level $\alpha=0.01$ is $t_{0.01}(4612)=2.58$. Since

$$
|t|>2.58
$$

the null hypothesis (2) is rejected at $1 \%$ significance level, i.e. the dependence of the number of points in the test in mathematics on the number of answers e) in tests variants exists. Using MS Excel we obtain furthermore regression line

$$
y=63.974-2.009 x
$$

From this regression line follows that expected the number of points in mathematics in the test variant with 0 answers e) is 63.974 and if the number of answers e) in tests variants increases by 1 , then the expected the number of points in mathematics decreases by 2.009 .

\section{Conclusion}

The differences between number of points in mathematics in test variants, which were used for the entrance examinations in mathematics at University of Economics in Prague in 2013, were analysed in present paper. The differences may arise due to the varying difficulty of the test variants, but also because of the different level of knowledge of students who write these variants. From [11] it follows that differences between results of tests variants may arise due to different level of knowledge of the students who wrote these variants. On the other hand, the difficulty of test variants for students is poorly measured. This problem was solved in the present paper. From results of the paper it follows that the number of points in the test in mathematics depends on the number of answers "e) another answer" in tests variants, but the dependence is very weak.

Acknowledgements. This paper was processed with contribution of long term institutional support of research activities by Faculty of Informatics and Statistics, University of Economics, Prague.

\section{References}

1. Anděl, J. (1978) Matematická statistika. Praha: SNTL/ALFA.

2. Brožová, H., Rydval, J. (2013) 'Analysis of the exam test quality', Efficiency and Responsibility in Education, Proceedings of the 10th International Conference, Prague, pp. 47-54.

3. Hrubý, M. (2013) 'Extended elements of the question objects', Efficiency and Responsibility in Education, Proceedings of the 10th International Conference, Prague, pp. 204-209.

4. Hrubý, M. (2016) 'Feedback improvement of question objects ', International Journal of Continuing Engineering Education and Lifelong Learning, vol. 26, no 2, pp. 183-195.

5. Kaspř́ková, N. (2012) 'Data analysis of students' performance', Efficiency and Responsibility in Education, Proceedings of the 9th International Conference, Prague, pp. 213-218.

6. Kaspř́íková, N., Klůfa, J. (2015) ‘AOQL Sampling Plans for Inspection by Variables and Attributes Versus the Plans for Inspection by Attributes', Quality Technology and Quantitative Management, vol. 12, no. 2, pp. 133-142.

7. Klůfa, J. (2012) 'Tests from probability point of view', Efficiency and Responsibility in Education, Proceedings of the 9th International Conference, Prague, pp. 229-233.

8. Klůfa, J., Eliášová, L. (2013) Matematika príprava k prijímacím zkouškám na VŠE, Prague: Ekopress. 
9. Klůfa, J. (2013) 'Comparison of entrance examinations in mathematics', Efficiency and Responsibility in Education, Proceedings of the 10th International Conference, Prague, pp. 270275.

10. Klůfa, J. (2015) 'Dependence of the Results of Entrance Examinations on Test Variants', Procedia - Social and Behavioral Sciences, vol. 174, pp. 3565-3571.

11. Klůfa, J. (2016) 'Analysis of the differences between results of test variants', Efficiency and Responsibility in Education, Proceedings of the 13th International Conference, Prague, pp. 279285

12. Kohanová, I. (2012) 'Analysis of university entrance test from mathematics', Acta Didactica Universitatis Comenianae Mathematics, vol. 12, pp. 31-46.

13. Kučera, P., Svatošová, L., Pelikán, M. (2015) 'University study results as related to the admission exam results' Efficiency and Responsibility in Education, Proceedings of the 12th International Conference, Prague, pp. 318324.

14. Marek, L. (2013) Statistika v príkladech, Prague: Professional Publishing.

15. Mošna, F. (2013) 'E-learning and interactive dynamical figures for teaching of mathematics', Efficiency and Responsibility in Education, Proceedings of the 10th International Conference, Prague, pp. 449-454.

16. Premadasa, I. (1993) 'A reappraisal of the use of multiple-choice questions', Medical Teacher, vol. 15, no. 2-3, pp. 237-242.

17. Rao, C.R. (1973) Linear Statistical Inference and Its Applications, New York: John Wiley

18. Zhao, Y. (2006) 'How to design and interpret a multiple-choice-question test: A probabilistic approach', International Journal of Engineering Education, vol. 22, no. 6, pp. 1281-1286. 